Primary Research

\title{
Reflexive Reflection Co-created with Kehte-ayak (Old Ones) as an Indigenous Qualitative Methodological Data Contemplation Tool
}

Carrie LaVallie, JoLee Sasakamoose

\section{A R T I C L E IN F O}

\section{Keywords:}

Reflexive Reflection

Indigenous methodologies

Aftercare services

https://doi.org/10.32799/ijih.v16i2.33906

\author{
A B S T R A C T
}

The aim of this paper is to propose a new way of understanding data contemplation for Indigenous methodologies. There is a need for Indigenous methods that allow us to explore and organize findings that are steeped in the contextualized story and grounded in the research relationship. A study that asked Cree Kehte-ayak (Old Ones) about the relevance in harmonizing Indigenous and Western ways of knowing in healing from addiction shows that Reflexive Reflection (RR) offers a respectful way for discovery. RR offers epistemological underpinnings for data consideration when engaging Indigenous methodologies. Culturally rooted addictions research can contribute to Indigenous wellness and cultural renewal by bringing awareness to the link between colonialism and addiction and by actively re-centring an Indigenous worldview and governance in the research process (Hall et al., 2015). While challenging colonialism is vital, the strength of Indigenous culture must be central to the overall project, with relational accountability that implies all parts of the research process are related, and that the researcher is responsible for nurturing and maintaining this relationship with the research process and with "all relations." Indigenous research inquiry involves moments of contemplation that explore dreams, intuition, teachings, and connection to land. It also involves spending intimate hours listening to stories of the "old ones" that are rooted in a sense of kinship responsibility that relay culture, identity, and a sense of belonging that are essential to the life of the researcher. Reframing the language around aftercare services for Indigenous Peoples can take place through reflexive investigation and knowledge creation.

\section{A U T HOR IN F O}

Carrie LaVallie, RPN, PhD, Assistant Professor, Indigenous Health Studies, First Nations University of Canada, Prince Albert, Saskatchewan, Canada. Email: clavallie@fnuniv.ca

JoLee Sasakamoose, PhD, Associate Professor, Educational Psychology and Counselling, University of Regina, Regina, Saskatchewan, Canada; Research Director, Indigenous Wellness Research Community Network \& Wellness Wheel Medical Clinic, Regina, Saskatchewan, Canada 


\section{Introduction}

The Truth and Reconciliation Commission of Canada (TRC, 2015) calls for closing the inequitable gaps in the wellbeing of Indigenous Peoples by addressing historic trauma as a central determinant of Indigenous health and by building capacity for the mobilization of Indigenous paradigms (TRC, 2015, Articles 18, 19, 22, 23). First Nations and Métis Peoples are asserting their perspectives by dismantling colonized research practices and calling for culturally responsive approaches that take into consideration Indigenous communities' land, language, values, beliefs, and protocols in the design, delivery, and implementation of research (Absolon, 2001; Battiste, 2008; Chilisa, 2012; Grande, 2004, 2008; Kovach, 2012; Resnicow et al., 2000; Tuhiwai Smith, 1999; Waters, 2004; Wilson, 2008). Strategies that promote First Nations and Métis community-driven research priorities are more appropriately advanced if methodological tools used for collection and analysis (a) shift perceived deficits away from the individual and place them in the appropriate context (e.g., residential schools, colonization) (Snowshoe \& Starblanket, 2016) and (b) work to ameliorate the impact of multigenerational trauma on families and communities (Mussell et al., 2004), further addressing the TRC's calls. The Cultural Responsiveness Framework (CRF) (Sasakamoose et al., 2017) is an example of a decolonizing, locally adaptable model that was developed for collecting data to improve Indigenous wellbeing. While methodologies for data collection have recently moved in the direction of Indigenouscentred approaches, we have yet to see an Indigenous method of data analysis. Thus, researchers must revert to Western qualitative methods that sort, code, and analyze as standard practice.

To address this gap, we engaged the CRF (Federation of Saskatchewn Indian Nations [FSIN], 2013; Sasakamoose et al., 2017) to co-construct the Reflexive Reflection tool (LaVallie, 2019; LaVallie \& Sasakamoose, 2016) to reflect on conversations held with Kehte-ayak (Old Ones) in an effort to improve addiction treatment aftercare services for people healing from addiction. The Reflexive Reflection tool is a research analysis method that was co-created to respectfully represent the process of data contemplation using an Indigenous methodological paradigm, as no one conventional qualitative method met the respectful, relational approach required for co-constructing knowledge with participants.

Kovach (2012) coined the term "cultural catalyst activities," which LaVallie (2019) described as "actions or activities sparked from Canadian Indigenous values that may include dreams, intuition, unique experiences, ceremony, inner voice, or prayer" (p. 12). Before and during the research process, the researcher should use vision and honour prophecies as guides to support research purpose and direction. Fiedeldey-Van Dijk et al. (2016) described these catalyst activities as cultural intervention practices (CIP) and empirically suggested that CIPs promote wellness and health outcomes among Indigenous people, thus enabling and anticipating healing potential for Indigenous research (FSIN, 2013; Sasakamoose et al., 2017). Indigenous research is itself a CIP by virtue of the processes that involve community engagement, ceremony, research creation, implementation, review, and knowledge mobilization with different levels of ceremonies as required. 


\section{Indigenous Research Ethics and Protocols}

\section{Background}

Currently, there are no laws protecting First Nations or Métis rights and interests when it comes to research, data, or information management, although very specific guidelines exist. Indigenous methodologies engage with and honour Métis and First Nations communities through protocols of respect and reciprocity (Kovach, 2012; Lavallée, 2009). This includes respecting community self-determination by ensuring researchers put in place values and mechanisms for interacting with Indigenous Peoples, such as First Nations Ownership, Control, Access and Possession (OCAP) $)^{1}$ and the Métis Ownership, Control, Access, and Stewardship Framework (First Nations, Metis and Inuit Health, 2013; First Nations Information Governance Centre, 2011). Overall, research processes should be guided by the principles implicit in Chapter 9 of the revised Tri-Council Policy Statement (TCPS2), which emphasizes the importance of community engagement, mutual benefits in research, collaborative research, and reciprocal collaborative research agreements as required (Canadian Institutes of Health Research [CIHR] et al., 2018). This chapter, titled "Research Involving the First Nations, Inuit, and Métis Peoples of Canada," is one of the few regulatory documents that aims to provide context and bridge the divide between researchers and Indigenous Peoples. The document recognizes research involving Indigenous Peoples has been conducted mainly by non-Indigenous researchers in Canada. It suggests that using a framework that respects Indigenous Peoples and does not neglect the ethics, protocols, and traditions of the communities researchers are working with is necessary to perform ethical research (CIHR, 2018). OCAP empowers communities to determine their own research processes, including knowledge creation, data management and storage, and knowledge translation and dissemination. OCAP has been widely operationalized in many Indigenous communities, enabling Indigenous Peoples to claim authority over their knowledge. These guidelines provide a shared language for stakeholders to use to carry out responsibilities (Crooks et al., 2013).

With approval from the University of Regina Ethics Board, Dr. LaVallie co-constructed a research process with Kehte-ayak to improve addiction treatment aftercare services for people healing from addiction. The process was initiated with a pipe ceremony. Kehte-ayak supported the proposed research process and offered guidance for movement forward. Each Kehtehi (Old One) reviewed their transcripts and findings. The Kehte-ayak embraced the research direction and used the new information gained in their own aftercare work. The researcher was encouraged to develop a contemplative method respecting the Kehte-ayak's local epistemology and language. Visits from animals, intuition, and tradition created this contemplative process. The research process was closed with a pipe ceremony and feast.

\section{Theoretical Underpinnings}

Decolonization, once considered to be the systematic process of handing over the instrument of government, is now recognized as a long-term process involving the bureaucratic,

\footnotetext{
${ }^{1}$ Standing for ownership, control, access, and possession, $\mathrm{OCAP}^{\circledR}$ is a registered trademark of the First Nations Information Governance Centre (FNIGC; https://fnigc.ca/ocap).
}

V OLUME 16 , IS S UE 2, $2021 \bullet 210$ 
cultural, linguistic, and psychological displacement of colonial authority (Smith, 1999/2012). Similarly, in recent years, Indigenous Peoples and scholars have worked tirelessly to establish decolonizing theoretical models and frameworks that emphasize Indigenous methodologies and ways of knowing alongside evidence-informed Western practices (Absolon, 2011; Battiste, 2008; Chilisa, 2012; Grande, 2004, 2008; Kirmayer et al., 2003; Kovach, 2012 Kovach, Carriere et al., 2015; Resnicow et al., 2000; Sasakamoose \& Pete, 2015; Snowshoe \& Starblanket, 2016; Tuhiwai Smith, 1999/2012; Waters, 2004; Waziyatawin \& Yellowbird, 2005; Wilson, 2008). With limitations, qualitative research honours some forms of Indigenous methods for data collection, such as narrative, storytelling, sharing circles (Fitznor, 1998), and self-location (Botha, 2012; Castleden et al., 2008; Gillies et al., 2014; Kovach, 2012; McIvor, 2010). Indigenous research inquiries can entail moments of contemplation in which to explore visions, intuition, teaching, and connection to language, culture, and land. Centred on Indigenous methodology, these approaches identify procedures that integrate Indigenous values, beliefs, protocols, and ways of knowing that are reciprocal, relevant, respectful, and responsible (Kovach, 2012; LaVallie, 2019; Smith, 1999/2012; Waters, 2004; Wilson, 2008). They promote culturally appropriate data collection but leave us desirous for Indigenous data contemplation tools.

\section{Challenges with Conventional Qualitative Data Analysis}

Although there are guidelines and safeguards, such as OCAP and TCPS2, there are few research methods and methodologies designed to address qualitative data contemplation in Indigenous communities or contexts. Western qualitative data analysis approaches fail because after the researcher "collects" knowledge, data is gleaned for themes and then classified within Western coding frameworks, resulting in findings that do not represent the population. Opencoding or data reduction is usually not useful in Indigenous research contexts. Thematic analysis is a traditional qualitative method that organizes recurrent ideas within the data rather than grounding themes in the lives and stories of participants.

Indigenous approaches consider the tensions of data reduction and representing decontextualized thoughts. Indigenous analytical approaches also interpret the dissection of stories as insensitive, as the effect of a story depends on the storyteller's interactions and relationships with those receiving the story (Simmonds \& Christopher, 2013).

Reflexive Reflection (RR) was developed to respect the researcher's process, knowledge, and learning with the investigation. RR fosters constructive data contemplation, as participants and researchers respond to each other's thoughts, forgotten information can resurface, and inhibitions are reduced by improving relationships during conversations (Merton et al., 1956). Gathering data on people's life experiences falls within Indigenous worldviews and is a common form of study and knowledge transfer within Indigenous societies. Historically, Indigenous Peoples have conducted research and passed on intergenerational information orally, through storytelling and conversational methods (Kovach, 2012). Research methods, whether they are Indigenous specific or not (e.g., sharing circles, interviews, focus groups), could be decolonized by using Reflexive Reflection as a contemplation tool. RR engages participants or community 
members as co-researchers in the research process to further improve relationship trust, draw on group strengths and resources, and incorporate shared knowledge and action (LaVeaux and Christopher, 2009; Lewis and Boyd, 2012).

The process of data contemplation discussed here suggests using the terms "reflection" or "contemplating" instead of "analyzing" to honour the multiple relationships created by Indigenous methodologies. The researcher reflects on the data by privileging the localized Indigenous ways of knowing in order to examine the researcher's positionality and then cocreate knowledge with the participants. Caretta and Jokinen (2017) present reflective research that reveals an intimate relationship with data and fieldwork. Sharing the inquiry's "emotional aspects" or the "lived experience" of the researcher is welcomed, as this discourse is rarely offered. RR offers insight into the reflexivity, positionality, and intersectionality of the researcher (Caretta and Jokinen 2017; Kwame 2017). LaVallie and Sasakamoose (2016) believe that reflexivity demonstrates the connection to the generated information, positionality exposes power imbalances, and intersectionality reveals the "multiple axes" of the researcher-participant relationship.

\section{Discussion}

\section{Indigenous Methodologies in Reflexivity}

Analysis methods used in any scholarly work must begin with a self-examination of personal beliefs. Indigenous Peoples have suffered from researchers who do not situate themselves regarding their biases, personal beliefs, and social and political agendas (Bishop, 2004). With Indigenous methodologies, a researcher is likely to adjust during the inquiry process due to co-constructed expertise. The researcher expresses their own reflexive reflection to encourage participants to focus on what they hear in a "reflexive" way. The researcher expresses how they experienced change from the inquiry process. From this standpoint, research can be applied as a catalyst to promote community dialogue and action. This can alleviate some of the barriers and underlines the potential of RR to be implemented as a promising gateway intervention in multiple Indigenous contexts (Kelly et al., 2014). LaVallie (2019) indicates that "Reflexive Reflection on the data allows the researcher to let go of concerns of generalizations and open their experience to universal guidance" (p. 96). The researcher considers why a particular quotation, experience, or finding appealed to them. Then, by pointing out their positionality and by understanding the relationship, privilege, and bias, the researcher makes the work personal.

Indigenous methodologies question prejudice and inequality and respect all ways of knowing through local epistemologies. Individuals are not centred; they are all related. Beliefs arise from a relational ontology and local epistemology. The researcher reframes each step of the inquiry process by co-constructing, not conducting, research.

In Indigenous methodologies, ceremony informs the researcher's purpose and approach to the experience. Power analysis is deepened by selecting specific, purposeful inquiry topics. Research results are not generalizable, but they launch a conversation about what is true for the 
people sharing the information. This "truth" is honoured as information. Local epistemology locates regional awareness. Solutions should not be the same for every area. Local epistemology avoids pan-Indigenous approaches. Participants are experts who facilitate the researcher to disseminate constructed knowledge. The dialogue is not theoretical, but practical; mutual responsibility exists between Indigenous and non-Indigenous researchers using local epistemology.

An Indigenous research agenda is healing, decolonizing, mobilizing, and transforming through self-determination, development, recovery, and survival (Absolon, 2011; Smith, 1999/2012). Kovach (2012) indicates that research inquiry should have a healing quality. The methods and process aid in redressing Canada's history of poor research done to Indigenous people.

Throughout the investigation, the researcher employs cultural catalysts or CIPs. For example, research with Indigenous communities is often centred on ceremonies and the use of traditional medicines, such as gifting tobacco in the form of tobacco ties, smudging, or sweat lodges, and should involve community Elders and Knowledge Keepers (Flicker et al., 2015). The researcher will engage in activities to express and affirm their goal, develop a research question and objectives, gather data, consider data, and disseminate findings. Through relationships, the researcher, spirit guides, and land interact to co-create new inquiries and findings.

\section{Reflexive Reflection as a Data Contemplation (analysis) Method}

We present the Reflexive Reflection tool as a decolonizing method of contemplating data in an Indigenous research context. When we are reflexive, we seek ways to challenge our behaviours, thinking processes, beliefs, theories, prejudices, and repetitive behaviour and try to clarify our diverse relationships with others (Bolton, 2005). It is a subtle but deliberate change to our self-awareness that can make a profound difference in research outcomes. RR is an approach that finds meaning in how things relate to each another and enables shared narratives for learning. It is suggested as a method of assessing the researcher's perception of the participants' experiences (LaVallie, 2019), presenting the hypothesis that the research process may provide a promising intervention to support the wellbeing of First Nations Peoples.

RR seamlessly maps the Cultural Responsiveness Framework's three strategic directions (FSIN, 2013; Lavallée, 2009; Sasakamoose et al., 2017; TRC, 2015). Established in communityspecific paradigms and harmonized with evidence-informed Western standards, RR is a culturally sensitive process that meets the epistemological bases for data consideration when engaging Indigenous methodologies. RR has been seamlessly mapped on the three strategic directions of the Cultural Responsiveness Framework: to restore Indigenous ways of knowing, create a middle ground for Indigenous and Western research, and decolonize health research by maintaining the reconciliatory mandate for pluralistic paradigmatic life (FSIN, 2013; Lavallee, 2009; Sasakamoose, et al., 2017; TRC, 2015). Established in community-specific paradigms and harmonized with evidence-informed Western standards, RR is a culturally sensitive process that meets the epistemological bases for data consideration when engaging Indigenous methodologies. Although RR's data contemplation method was designed to operate in the field 
of addictions research, it is adaptable and may apply to any topic or research approach as it acts as a deeper level of data contemplation and data co-construction. It serves as a decolonizing tool as it builds relationships between researcher and members/participants. In data reflection, natural processes shift toward data mobilization and sharing. The process of individual and group/community reflection and reflexive review strengthens the researcher to develop culturally responsive research skills while adapting local research approaches. The RR method claims that knowledge creation, sharing, and mobilization foster community capacity and skills for culturally sensitive data contemplation.

Offered as a stand-alone, or compatible with other qualitative analytical methods, RR was developed to reflect the process of considering data within an Indigenous methodological framework. In the addiction study, the voices of Kehte-ayak (Old Ones) focused on how to improve addiction aftercare by decolonizing current practises and improving cultural responsiveness. Following the Kehte-ayak cultural protocols, ethical approval was obtained and ethical guidelines were followed. Stories and narratives presented an image of mutual understanding between knowledge holders and the researcher. Quotations and illustrations include common data representation (Bird et al., 2009). The data in the Kehte-ayak study was not analyzed; it was reflected upon through a reflexive mode. Therefore, with the Kehte-ayak, LaVallie transformed conventional analysis into a reflexive practice that respects the need for knowledge creation and sharing between researcher and participants.

\section{Indigenous Modified Metaphor Analysis}

Indigenous research is a sophisticated, decolonized approach to generating, interrogating, validating, and disseminating information based on the cosmology or worldview of Indigenous Peoples (Sefa De, as cited in Coburn, 2013). Only wholistic Indigenous research, rooted in facets of individual and human collective experience, can be fully interpreted. Engaging Indigenous traditions is a way to respect and renew Indigenous knowledges that were often discredited by colonialism. Wholistic interpretations may include a function for intuition, dreams, and ceremony that are often omitted from highly codified textual accounts, despite informing Western research in practice (Coburn, 2013, p. 53).

Indigenous wisdom is steeped in metaphor. As well, there are many addiction metaphors (Akers et al., 2014). We chose to modify standard metaphor analyses in the creation of RR, as RR was used to express the relational experience of individuals dealing with addiction and addiction research (informed by Akers et al., 2014; Koc, 2015; Lakoff \& Johnson, 2003; Pragglejaz Group, 2007; Shinebourne \& Smith, 2010). Indigenous methodologies encourage metaphors, although when reflecting on Kehte-ayak knowledge, little has been published using metaphor analysis. In addition, the analysis of metaphors relies heavily on the quantitative aspect of data analysis. Metaphors can assist people recovering from addiction by providing narratives that make sense of their experience. The standard narrative analysis allows for metaphorical arrangement, but the researcher co-constructing new knowledge misses the reflexive reflection offered. Although we chose metaphor as an analysis tool, RR can be adapted to methods that 
work best for the Indigenous context, and studies where this tool is locally adapted should be included in future study.

Metaphors are only shared when the researcher is influenced by their meaning. The researcher provides their own experience of change as part of the contemplation. It is not important whether the community uses this as an output for their study. What is essential is that while providing personal insights, the researcher marinates in their experience. RR offers regular iteration as a form of data contemplation that enables the researcher to select the best approach, which is localized to the population and applied in a culturally responsive manner. This could become a leading contemplation tool for the achievement of clinically driven research (Aral \& Blanchard, 2012).

The researcher explores their experience of the research process and data by offering space for intuition, dreams, and ceremony. Reflexive data reflection allows the researcher to drop assumptions and opens them to new learning. Instead of focusing on data, finding metaphors, and using conventional metaphor contemplation techniques, the researcher explores their own perceptions and awakenings to reveal how they adapted in response to metaphors within the data that spoke to them. Researchers are expected to consider why they chose a standpoint, recognizing their positionality. The process of questioning researcher privilege by objectively presenting subjective reactions to data decolonizes Western science. The work is subjective, and because of collaborative research relationships, the researcher should understand the challenge of describing their understandings and improvements.

\section{Indigenous Reflexive Reflection Contemplation Process}

Dr. LaVallie's co-constructed RR method was a valuable tool to explain how the Kehteayak talked about harmonizing Indigenous and Western ways of knowing while walking alongside people healing from addiction. The Cree Kehte-ayak gave teachings and stories during research conversations. To use Reflexive Reflection, the researcher examines the intention for inquiry, the fieldwork notes, and their self-location (Kovach, 2012) in order to reflect on the experience and information. Ideally, this is done in a contemplative setting or in nature. Many Indigenous researchers will take their data into a ceremony at this stage, seeking guidance from the ancestors and Kehte-ayak (Sasakamoose \& Pete, 2015). LaVallie used the conversation method (Kovach, 2010) and sharing circles with Kehte-ayak to explore how to harmonize Indigenous and Western ways of knowing in addiction aftercare services. RR provides the researcher with space to contemplate the research experience alongside the data review and assess it for insights. Informal discussions are held, deepening relationships with participants, knowledge holders, and Kehte-ayak to ensure proper understanding of metaphors and teachings. As researchers and participants in the Kehte-ayak study analyzed interactions and notes, they noticed what drew their attention. The researcher was unfamiliar with some of the concepts revealed during interviews but was flexible and open to the material. Indigenous metaphors came across powerfully, and a Cree interpreter brought understanding to the Indigenous knowledge offered. 


\section{Applying Reflexive Reflection Contemplation: Examples from an Addictions Study}

Reflexive Reflection was used to contemplate data exploring the importance of harmonizing Indigenous and Western ways of addiction healing. The metaphor "Moniyaw (white) ways are not working" came out of the data. This metaphor describes a way of being; the "white" way of being. This way of being was described as unhelpful to Indigenous people healing from addiction. Aftercare is the term used for post-intervention support services that mostly follow a Western paradigm. These services limit long-lasting pimatisiwin (a good way of life; healthy lifestyle). It was stated that the Moniyaw way lacks relationship and connection (that is, it is individualistic) and lacks historical and socio-cultural Indigenous context. One Kehtehi (Old One) in the study revealed that they got a certificate from an "Indigenous" addiction education program but learned nothing about Indigenous healing practices. The Indigenous content and activities presented were "Western approved."

Kehtehi- "I have my diploma in addictions, and they didn't teach traditional beliefs. The old ways and how it's really supposed to be taught. They didn't teach that in university, and I don't think they ever will."

Researcher- "You would think that they would have some Indigenous content or perspective or approach, but it's a Western diploma process."

Kehtehi-"Yes."

Researcher-“That's interesting."

Kehtehi- "But they'll allow ..."

Researcher- "Smudging?"

Kehtehi_- "Yes, but this is it. A different institution may allow a sweat. Maybe."

When the Kehtehi took an addiction education program, they were surprised to realize that the program was Western-based and offered platitudes regarding Indigenous healing. Indigenous ways of being are not merely smudging or sweats; they are a paradigm. Through relational ontology, people believe we are all related. Our connections are understood through teachings and stories. The next conversation expands on how Western treatment programs establish a paternalistic care hierarchy. Hierarchies create power imbalances and suppress marginalized people's voices.

Researcher-"How would you see healing different than through a Western perspective?" 
Kehtehi- "Well ... I know the answer. The [therapists] put themselves on a pedestal, and they won't give up that reign, that hold, and they'll keep the person in treatment for too long."

Researcher-"What do you mean by that?"

Kehtehi- "Well, I don't know if that's a sense of power and control, but I see people in treatment, and I'm thinking, oh, that's too damn long. You shouldn't be in there that long. You need to go in there, empower them, and let them fly and let them learn through experiences, whether they fall or not. Falling is a good thing. When somebody says, I quit drinking. Okay, that's good. And when they fall, awesome, what did you learn from that? You don't smack anybody from that. Okay, that's good, you fell. What did you learn from that? You're lucky you fell. Look at all these beautiful teachings that you learned. Make it a positive experience."

Researcher- "As opposed to punishment."

Kehtehi-"Yeah."

The researcher reflected on the teachings of the Kehtehi realizing that the Universe's experiences were lessons or teachings. The Kehtehi's approach is unlike Western knowledge systems. People healing from addiction are expected to navigate aftercare services with an abstinence approach. Many aftercare providers believe in a harm reduction approach, but paradigms of abstinence and harm reduction do not always support an Indigenous worldview.

A third Kehtehi revealed that they tried following Alcoholics Anonymous (AA) many times, but it did not fit with what they needed.

Kehtehi- "Yeah. When I was in AA, when I tried to help myself before, I had no support but I was trying AA. Inventory—is it step four, inventory?"

Researcher-"I think so, yeah."

Kehtehi- "Yeah. I couldn't do it; it was so hard for me and I didn't know where to go to."

Researcher-"Yeah. I think a lot of people stumble there and then relapse."

Kehtehi-"Yeah, and I relapsed. But you know, I-like I said, in the traditional way it seemed a lot easier for me, you know when the [Kehte-ayak] told me what to do. You know so simple and basic that it was a lot easier than, you know, doing step four in the Western way."

In AA, the individual recovering from addiction is left to explore their transgressions alone while not in a healing relationship. Cultural approaches to healing establish a healthy 
environment where individuals are supported and are mentored alongside someone while seeking wellness. When multiple resources are employed, healing is then accelerated. The resources are most effective when the person healing feels safe to express their culture within those services. Reflexive Reflection supported the researcher in challenging power imbalances and using figurative language that reflected what the Kehte-ayak taught them. A translator helped clarify the Cree terminology.

This Kehtehi recalled how they felt when they started the path to healing following Indigenous, not Moniyaw, ways.

Kehtehi- "And then as soon as I started walking this path, I felt a comfort, it was comfortable. Because I wasn't raised this way, Christianity was really strong in my family. I guess it's just a little mixture of everything. ... It's not working for our people, period. It's not working. Like if it's not going to work for me, then what else are they doing different to help another person that it's not working for?"

No single aftercare method works for all individuals. Services that integrate different methods of understanding are more effective. A definite step toward eliminating bigotry and creating a culturally safe space is to respect the voice of the individual who is healing. This study showed the researcher that Moniyaw approaches did not work and that Indigenous ways and Western ways of healing needed to be harmonized. Harmonizing ways can lead to challenges. Some providers of aftercare services claim Western knowledge is superior. The following Kehtehi shares that trying to harmonize ways can be viewed as a destructive act.

Kehtehi- "And I said it's nice to have you working in our reserve, but it's always nice to have our First Nation people to work with our people. I said there's two hands, they have to join together, and the First Nation and the non-like the white people. I said I'm not trying to discriminate you, I said I'm trying to make my point. I said how nice it would be to work together, you know, as [Kehte-ayak]."

The researcher, using Reflexive Reflection, considered what the Kehte-ayak were sharing. To state as a metaphor that Moniyaw ways are not working clearly articulates an understanding of why Indigenous healing practices must stem from Indigenous ways of healing. With the notion of deeper levels of conscious reflection, the RR approach departs from quantitative or qualitative coding and instead shifts toward exploring the perceptions of teachings that develop in the researcher's consciousness during research inquiry. The researcher introduces to the participants the "understandings" received from reflexive reflection and the metaphors that originated from the narratives. Indigenous methodologies are used to represent the knowledge that moves away from generalization and challenges the researcher to review concrete teachings. To find meaning, the researcher uses their relationship with the data. In relational space, the themes become personal and the middle ground is established to support culturally responsive 
research (Sasakamoose et al., 2017). Relevant knowledge is provided to the participants through the researcher's experience lens. In a somewhat autobiographical exploration, the researcher, along with the participants, reflects on the data, describes teaching metaphors and definitions, and discusses how the researcher has changed from the research process. During the data collection, the researcher pays attention to physiological and environmental cues that direct the researcher to connect to the data. Notes taken during and after data collection alert the researcher to which statements resonated during the process. While reviewing transcripts, the researcher flags culturally relevant language to focus on the meaning. With participants, the researcher reviews metaphors and meanings to deepen the relationship. Knowledge holders, Kehte-ayak, participants, and the researcher discuss personal changes from the teachings provided by data collection. Metaphors, teachings, and reflections shared build new awareness, informing a new path forward. Indigenous methodologies expect decolonization of privileged language, as, for example, in the study of addiction, Cree language was used to communicate metaphors.

\section{Conclusions}

Historically, research regarding Indigenous Peoples has not been led or conducted by Indigenous scholars or academics, and this neglect has yielded less than favorable research results (Brant Castellano, 2004). The lack of culturally responsive services delivered to Indigenous Peoples contributes to poor health outcomes and underutilization of services (Sasakamoose, et al., 2017). This response is partly because socially and economically disadvantaged peoples are less likely to react positively to solutions suggested by experts external to their communities. RR as a data reflection tool allows for the identification of strengths and community protective factors to inform the next stages of new and applicable information. This looping facilitates a learning health system with time-sensitive feedback, mobilizing the translation of effective strategies immediately back to the community members (Blanchard \& Aral, 2010).

\section{Reflexive Reflection is a promising method of Indigenous research and data} consideration. As a new method, its utility in Indigenous research is not yet known. Further application in multiple contexts can provide insight into RR's viability as a stand-alone or additional complementary method of data contemplation. Historically, Indigenous Peoples have studied and transmitted oral intergenerational learning through conversational data collection such as storytelling (Kovach, 2010). While the approach or methodology used may not, in reality, be Indigenous in itself, if the approach or methodology is compatible with the philosophy of Indigenous worldviews, it may be adapted to the data collected. Using Reflexive Reflection allows participants or communities to be recognized in the process, draws on community strengths and resources, fosters reciprocal partnerships, integrates shared knowledge and action, and fosters mutual learning (LaVeaux \& Christopher, 2009; Lewis \& Boyd, 2012).

While this paper focuses primarily on the collection and interpretation of qualitative data, quantitative processes have advantages. While quantitative methodologies are not always compatible with Indigenous ways of being, aligning quantitative approaches with the RR 
approach may yield results that can provide a comprehensive picture of the study context. Combining quantitative approaches harmonized with the data contemplation of the RR approach may generate results that can provide a detailed picture of the research topic. The methods should be community-driven to be relevant and culturally responsive. We assume RR is ideal for aligning with approaches such as focus groups, sharing circles, and even one-on-one interviews involving community members in telling their stories and experiences. Ultimately, Indigenous research should still be done for the community's benefit and, where possible, directed by Indigenous researchers.

RR starts by realizing that various sources of community-based experience and knowledge can influence research as it is conceptualized, planned, and conducted, and that collaborative research contemplation can prevent many of the abusive research methods that have had an impact on the past.

\section{References}

Absolon, K. (2011). Kaandossiwin: How we come to know. Fernwood.

Akers, L., Gordon, J., Rayna, S., \& Severson, H. (2014). Metaphors of smokeless tobacco addiction and cessation. Addiction Research and Theory, 22(1), 49-56. https://doi.org/10.319/16066359.2013.763933

Aral, S. O., \& Blanchard, J. F. (2012). The Program Science initiative: Improving the planning, implementation and evaluation of HIV/STI prevention programs. Sexually Transmitted Infections, 88(3):157-159. http://dx.doi.org/10.1136/sextrans-2011-050389

Battiste, M. (2008). Research ethics for protecting Indigenous knowledge and heritage: Institutional and researcher responsibilities. In N. Denzin, Y. Lincoln, \& L. Tuhiwai Smith (Eds.), Handbook of critical and Indigenous methodologies (pp. 497-509). Sage Publications Inc. https://doi.org/10.4135/9781483385686.n25

Blanchard, J. \& Aral, S. (2010). Emergent properties and structural patterns in sexually transmitted infection and HIV research. Sexually Transmitted Infections, 86(Suppl 3), iii49. DOI: $10.1136 /$ sti.2010.046037

Bird, S., Wiles, J., Okalik, L., Kilabuk, J., \& Egeland, G. (2009). Methodological consideration of story telling in qualitative research involving Indigenous Peoples. Global Health Promotion, 16(4), 16-26. https://doi.org/10.1177/1757975909348111

Bishop, A. (2004). Becoming an ally: Breaking the cycle of oppression. Fernwood.

Bolton, G. (2005) Reflective practice writing for professional development (2nd ed). London Sage Publications.

Botha, R. (2012). Evolving leadership required in South African schools. Research in Education, 88(1), 40-49. https://doi.org/10.7227/RIE.88.1.4

Brant Castellano, M. (2004). Ethics of Aboriginal research. International Journal of Indigenous Health, 1(1), 98-114.

Canadian Institutes of Health Research, Natural Sciences and Engineering Research Council of Canada, and Social Sciences and Humanities Research Council. (2018). Tri-Council Policy

V OLUME 16 , IS S UE 2, $2021 \bullet 220$ 
Statement: Ethical Conduct for Research Involving Humans. Government of Canada. http://www.pre.ethics.gc.ca/eng/policy-politique_tcps2-eptc2_2018.html

Caretta, M., \& Jokinen, J. (2017). Conflating privilege and vulnerability: A reflexive analysis of emotions and positionality in postgraduate fieldwork. The Professional Geographer, 69(2), 275-283. https://doi.org/10.1080/00330124.2016.1252268

Castleden, H., Garvin, T., \& Huu-ay-aht First Nation. (2008). Modifying Photovoice for community-based participatory Indigenous research. Social Science and Medicine, 66(6), 1393-1405. https://doi.org/10.1016/j.socscimed.2007.11.030

Chilisa, B. (2012). Indigenous research methodologies. SAGE Publications.

Coburn, E. (2013). Indigenous research as resistance. Socialist Studies, 9(1), 51-63. https://doi.org/10.18740/S40017

Crooks, C. V., Snowshoe, A., Chiodo, D., \& Brunette-Debassige, C. (2013). Navigating between rigour and community-based research partnerships: Building the evaluation of the Uniting Our Nations health promotion program for FNMI youth. Canadian Journal of Community Mental Health, 32(2), 13-25. https://doi.org/10.7870/cjcmh-2013-016

Federation of Saskatchewan Indian Nations. (2013). Cultural Responsiveness Framework. http://allnationshope.ca/userdata/files/187/CRF\%20-\%20Final\%20Copy.pdf

Fiedeldey-Van Dijk, C., Rowan, M., Dell, C., Mushquash, C., Hopkins, C., Fornssler, B., \& Shea, B. (2016). Honoring Indigenous culture-as-intervention: Development and validity of the Native Wellness Assessment. Journal of Ethnicity in Substance Abuse, 16(2), 181218. https://doi.org/10.1080/15332640.2015.1119774

Fitznor, L. (1998). The circle of life. Affirming Aboriginal philosophies in everyday life. In D. C. McCance (Ed.), Life ethics in world religions (pp. 21-39). Scholars Press.

First Nations, Metis and Inuit Health. (2013). Framework for research engagement with First Nation, Metis, and Inuit Peoples. University of Manitoba.

https://umanitoba.ca/faculties/health_sciences/medicine/media/UofM_Framework_Report_ web.pdf

First Nations Information Governance Centre. (2011). First Nations Regional Health Survey: Best practice tools for OCAP compliant research. http://fnigc.ca/sites/default/files/RHSBestPracticeBooklet.pdf

Flicker, S., O’Campo, P., Monchalin, R., Thistle, J., Worthington, C., Masching, R., Guta, A., Pooyak, S., Whitebird, W., \& Thomas, C. (2015). Research done in "A Good Way": The importance of Indigenous Elder involvement in HIV community-based research. American Journal of Public Health, 105(6), 1149-1154. https://doi.org/10.2105/AJPH.2014.302522

Gillies, C., Burleigh, D., Snowshoe, A., \& Werner, D. (2014). Walking in circles: Self-location in Indigenous youth violence prevention research. First Nations Perspectives Journal, 6(1), $5-25$.

Grande, S. (2004). Red Pedagogy: Native American social and political thought. Rowman \& Littlefield. 
Grande, S. (2008). Red pedagogy: The un-methodology. In N. Denzin, Y. Lincoln, \& L. Tuhiwai Smith (Eds.), Handbook of critical and Indigenous methodologies (pp. 233-254). Sage Publications. https://doi.org/10.4135/9781483385686.n12

Hall, L., Dell, C., Fornssler, B., Hopkins, C., Mushquash, C., \& Rowan, M. (2015). Research as cultural renewal: Applying two-eyed seeing in a research project about cultural interventions in First Nations addictions treatment. The International Indigenous Policy Journal, 6(2). https://doi.org/10.18584/iipj.2015.6.2.4

Kelly, E., Fulginiti, A., Pahwa, R., Tallen, L., Duan, L., \& Brekke, J. S. (2014). A pilot test of a peer navigator intervention for improving the health of individuals with serious mental illness. Community Mental Health Journal, 50(4), 435-446. https://doi.org/10.1007/s10597-013-9616-4

Kirmayer, L., Simpson, C., \& Cargo, M. (2003). Healing traditions: Culture, community and mental health promotion with Canadian Aboriginal people. Australasian Psychiatry, 11 (Suppl.), 15-23. https://doi.org/10.1046/j.1038-5282.2003.02010.x

Koc, M. (2015). Using metaphors to investigate cognition-behaviour link in problematic internet use among college students. Asia-Pacific Psychiatry, 7, 314-322. https://doi.org/10.1073/pnas.100777910710.1111/appy.12150

Kovach, M. (2010). Conversational method in Indigenous Research. First Peopls Child \& Family Review, 5(1), 40-48.Kovach, M. (2012). Indigenous methodologies: Characteristics, conversations and contexts (3rd ed.). University of Toronto Press.

Kovach, M., Carriere, J., Montgomery, H., Barret, M. J., \& Gillies, C. (2015). Indigenous presence: Experiencing and envisioning Indigenous knowledges within selected postsecondary sites of education and social work. https://education.usask.ca/documents/profiles/kovach/Indigenous-Presence-2014-KovachM-et-al.pdf

Kwame, A. (2017). Reflexivity and the insider/outsider discourse in Indigenous research: My personal experiences. AlterNative: An International Journal of Indigenous Peoples, 13(4), 1-8. doi.org/10.1177/1177180117729851

Lakoff, G., \& Johnson, M. (2003). Metaphors we live by. University of Chicago Press. https://doi.org/10.7208/chicago/9780226470993.001.0001

Lavallée, L. F. (2009). Practical application of an Indigenous research framework and two qualitative Indigenous research methods: Sharing circles and Anishnaabe symbol-based reflection. International Journal of Qualitative Methods, 8(1), 40. https://doi.org/10.1177/160940690900800103

LaVallie, C. (2019). Onisitootumowin kehte-ayak (the understanding of the old ones) of healing from addiction [Doctoral dissertation]. University of Regina.

LaVallie, C., \& Sasakamoose, J. (2016, June 22-24). Healing from addictions through the voices of Elders [Panel on traditional knowledge and research]. Annual Conference of Canadian Indigenous/Native Studies Association, Regina, SK, Canada.

LaVeaux, D., \& Christopher, S. (2009). Contextualizing CBPR: Key principles of CBPR meet the Indigenous research context. Pimatisiwin, 7(1), 1-16. 
Lewis, J., \& Boyd, K. (2012). Determined by the community: CBPR in Alaska Native communities building local control and self-determination. Journal of Indigenous Research, 1(2). https://digitalcommons.usu.edu/kicjir/vol1/iss2/6

McIvor, O. (2010). I am my subject: Blending Indigenous research methodology and authoethnography through integrity-based, spirit-based research. Canadian Journal of Native Education, 33(1), 137-151.

Merton, R. K., Fiske, M., \& Kendall, P. (1956). The focused interview: A manual of problems and procedures. Free Press.

Mussell, B., Cardiff, K., \& White, J. (2004). The mental health and well-being of Aboriginal children and youth: Guidance for new approaches and services [A research report prepared for the British Columbia Ministry of Children and Family Development]. Sal'i'shan Institute and University of British Columbia. https://childhealthpolicy.ca/wpcontent/themes/chpc/pdf/RR-8-04-full-report.pdf

Pragglejaz Group. (2007). MIP: A method for identifying metaphorically used words in discourse. Metaphor and Symbol, 22(1), 1-39. https://doi.org/10.1080/10926480709336752

Resnicow, K., Soler, R., Braithwaite, R. L., Ahluwalia, J. S., \& Butler, J. (2000). Cultural sensitivity in substance use prevention. Journal of Community Psychology, 28(3), 271290. http://dx.doi.org/10.1002/(SICI)1520-6629(200005)28:3<271::AIDJCOP4>3.0.CO;2-I

Sasakamoose, J., Bellegarde, T., Sutherland, W., Pete, S., \& McNabb, K. (2017). Miyopimatisiwin developing Indigenous Cultural Responsiveness Theory (ICRT): Improving Indigenous health and well-being. International Indigenous Policy Journal, 8(4). https://doi.org/10.18584/iipj.2017.8.4.1

Sasakamoose, J., \& Pete, S. (2015). Towards Indigenizing university policy kakwe-iyiniwasta kihci-kiskinwahamâtowikamikohk wiyasiwâcikanisa. Education Matters, 3(1).

Shinebourne, P., \& Smith, J. (2010). The communicative power of metaphors: An analysis and interpretation of metaphors in accounts of the experience of addiction. Psychology and Psychotherapy: Theory, Research and Practice, 83, 59-73. https://doi.org/10.1348/147608309X468077

Simmonds, V., \& Christopher, S. (2013). Adapting western research methods to Indigenous ways of knowing. American Journal of Public Health, 103(12), 2185-2192. https://doi.org/10.2105/AJPH.2012.301157

Smith, L.T. (2012). Decolonizing methodologies: Research and Indigenous people. Zed Books. (Original work published 1999)

Snowshoe, A., \& Starblanket, N. V. (2016). Eyininiw mistatimwak: The role of the Lac La Croix Indigenous Pony for First Nations youth mental wellness. Journal of Indigenous Wellbeing: Te Mauri-Pimatisiwin, 1(2), 60-76. https://journalindigenouswellbeing.com/journal_articles/eyininiw-mistatimwak-the-role-ofthe-lac-la-croix-indigenous-pony-for-first-nations-youth-mental-wellness/ 
Truth and Reconciliation Commission of Canada. (2015). Honouring the truth, reconciling for the future: Summary of the final report of the Truth and Reconciliation Commission of Canada.

http://www.trc.ca/assets/pdf/Honouring_the_Truth_Reconciling_for_the_Future_July_23_ 2015.pdf

Tuhiwai Smith, L. (1999). Decolonizing methodologies: Research and Indigenous people. Zed Books.

Waters, A. (2004). Introduction. In A. Waters (Ed.), American Indian thought. Blackwell.

Waziyatawin, \& Yellow Bird, M. (2005). Beginning decolonization. In Waziyatawin \& M. Yellow Bird (Eds.), For Indigenous eyes only: A decolonization handbook (pp. 1-8). School for Advanced Research Press.

Wilson, S. (2008). Research is ceremony: Indigenous research methods. Fernwood. 